\title{
DEVELOPMENT OF A PRIVATE REHABILITATION UNIT - AN EXPERIENCE
}

\section{Aphrodite Kastanos MSc \\ Physiotherapy \\ Diana Speer MCSP}

\section{INTRODUCTION}

Facilities available for specialised neurological and orthopaedic rehabilitation, based on the principle of a multidisciplinary approach, are very limited in South Africa. This type of specialised treatment has primarily been available at academic hospitals and those hospitals under the control of the mining industry. The resources available in these sectors have been put under enormous strain, thus limiting the quantity and quality of rehabilitation offered to the physically disabled.

\section{Barney Hurwitz Medical Institute}

In November 1991, the directors of a large group of hospitals agreed to convert an already existing hospital into a private rehabilitation institute that would cater for both in- and out-patients. A neurologist and therapists were involved in setting up the departments of physiotherapy, occupational therapy, speech therapy and social work. Nursing staff were responsible for setting up the wards for in-patients.

In February 1992, the establishment was opened, admitting post-acute neurologically impaired and poly-trauma

\section{continued from page 42}

10. Kigin CM. Chest physical therapy for the acutely ill medical patient. Phys Ther 1981;61:1724-36.

11. King M, Phillips DM, Gross Det al. Enhanced tracheal mucus clearance with high frequency chest wall compression. Am Rev Respir Dis 1983;128:511-5.

12. Mackenzie CF, Imle PC, Ciesla N. Chest Physiotherapy in the Intensive Care Unit. Second Edition. Baltimore, Hong Kong, London, Sydney: Williams \& Wilkins, 1989:6988,146-8,241.

13. Mackenzie CF, Shin B, McAslan TC. Chest physiotherapy: The effect on arterial oxygenation. Anesth Analg 1978;57:28-30.

14. Marini JJ, Pierson DJ, Hudson LD. Acute lobar atelectasis: a prospective comparison of fibreoptic bronchoscopy and respiratory therapy. Am Rev Respir Dis 1979;119:971-8.

15. Newton DA, Stephenson A. Effect of physiotherapy on pulmonary function. A laboratory study. Lancet 1978;2:228-9,

16. Pavia D, Thompson ML, Philliparos D. A preliminary study of the effect of a vibramat pad on bronchial clearance. Am Rev Respir Dis 1976;113:92-96.

17. Van Eeden SF. Notes on chest injuries for Intensive Care student nurses (in Afrikaans) 1990, University of Stellenbosch.

18. Wollmer P, Ursing K, Midgren B et al. Inefficiency of chest percussion in the physical therapy of chronic bronchitis. Eur J Respir Dis 1985;66:233-9. patients for intensive rehabilitation. Within six weeks it was recognised that the staff establishment needed to be expanded. By the end of May 1992, allied medical staff complement consisted of 2.5 physiotherapists, one occupational therapist, one social worker, 0.5 speech therapist, under a rehabilitation coordinator. A clinical psychologist was available on referral.

On admission to the institute, patients were assessed by each speciality, after which the therapists would confer and contract with the patient/caregiver. This allowed the patient and therapist a specific time to reach predetermined goals, as well as preparing the home environment for discharge of the patient.

The patients day was structured so that he was involved in a full day therapy programme with therapeutic activities being carried over in the ward. The programme also included a day or weekends at home prior to discharge from the ward whereafter outpatient therapy could continue. In addition full day, half day or sessional programmes were available to out-patients.

Liaison between disciplines included weekly ward meetings involving medical, nursing andallied medical staff as well as a weekly outpatient meeting.

\section{Problems}

\section{Financial}

Although the hospital charged medical aid tariffs, a significant number of patients' medical aids had reached the limit of benefits while the patient was still in an acute care hospital.

Representative Association of Medical Schemes (RAMS) refused to pay for services rendered by the therapists in the employ of the hospital.

Government gazetted codes as set out by RAMS for physiotherapy do not include a tariff for patients receiving extended periods of rehabilitation, or for assistants carrying out supervised exercise programmes.

Staff

The hospital required specialists in fields of physiotherapy, occupational therapy, speech therapy, social work and nursing. such specialists are scarce and required appropriate remuneration.

Legislation did not allow physiotherapists to be employed by any organisation/person other than the state, the mines of an independent physiotherapist.

\section{Discussion}

The establishment of a private rehabilitation institute in South Africa is an innovative and exciting concept. However, our medical resources do not provide for the comprehensive treatment and reintegration of the neurologically impaired individual into society. In many cases, by the time the patients were medically stable and ready for rehabilitation, they had reached the limit of their medical aid benefits and thus could not afford further treatment. This resulted in patients being discharged before reaching their maximal functional potential. Going home still functionally dependent to a unprepared environment puts considerable emotional and financial strain on family and caregivers.

Large institutions running on business principles cannot provide this type of service without showing a profit. Specialised therapists providing a professional service need to be suitably remunerated. Thus a balance must be found between the needs of society and the financial practicalities of running a private rehabilitation institute.

The cost of setting up a rehabilitation centre is substantial. Therefore, the benefits to the patient and community need to be critically appraised. Literature has indicated that rehabilitation in diagnostic groups is of maximal benefit predominantly due to the uniform approach to management (Flicker, 1989). This team approach should engender high moral, amongst the members and initiate research which acts as a catalyst to improve patient care and standards of treatment.

Literature indicates patients rehabilitated on stroke units / wards leave hospital sooner than those on general medical wards (Millikan, 1979). This implies that hospital costs per patient may be less on a stroke unit (Stevens et al, 1984). Results indicate a higher proportion of patients discharged from stroke units were independent compared with those from general medical units (Garraway et al 1980). Garraway found the mean length of stay in the stroke unit was 55 days in comparison to 75 days in a general medical ward. However, at one year follow-up the stroke unit benefit was no longer evident. Ongoing community follow-up is more likely to be utilised by those patients who received rehabilitation in a stroke unit (eg district nurses, physiotherapists and day centres) (Garraway et al 1981).

Studies comparing formalised neurorehabilitation with non-formalised treatment in functional and cognitive skills have been undertaken. Results show those patients who took part in the formalised programme gained a greater functional capacity with implications for return to work and decreased cost to, society (Mackay). There is now clear evidence as to the benefit to patients and cost effectiveness of skilled and appropriately delivered neurorehabilitation (Brooks, 1991). 
At the BHMI a tendency towards the above results was experienced. Unfortunately because of the aforementioned problems, completed results cannot be quoted.

\section{Suggestions:}

Prior to opening a rehabilitation centre which will provide the necessary service, all the legalistic and financial implications must be cleared. This includes permission being granted from the ruling bodies allowing therapists to be employed by hospitals. (Permission can be obtained if motivated - Editor)

Approval must be gained for a composite fee for a rehabilita tion package, that will be carried out in an approved rehabilitation environment that provides all the necessary equipment. A package could be worked out depending on the amount and type of therapies required.

The allied medical staff structure should run parallel to the nursing staff with its own hierarchy, thus having a rehabilitation coordinator, senior, junior staff and assistants.

Considering the facilities currently available at the BHMI, patients admitted for rehabilitation could be separated into diagnostic groups. Each group differentiated into its own specialised units/wards allowing for optimal use of these available facilities (eg hydrotherapy pool and ADL centre).

\section{Conclusions:}

Due to these financial and personnel problems, the institute has, of necessity, adapted in order to continue providing this specific service. The institute has established gerontology and general rehabilitation wards. The therapists are no longer employed by the institute and are registered with their specific professional bodies as individual private practitioners. Liaison between team members has remained high, the cornerstone of which is the weekly team meeting during which goals of treatment, social and economic matters pertaining to the patient are discussed.

It should be noted that with the restructuring of medical aid regulations, in 1994, provision for the establishment of rehabilitation units will hopefully be made, either as separate clinics or as specific units within existing hospitals. The recognition of the need for such units and acknowledgment of the benefit to patients who are treated in these establishments must be brought to the attention of those at government level as well as the general population.

\section{References}

1. Brooks N. The Effectiveness of Post Acute Rehabilitation. Brain Injury 1991;5:103-110.

2. Flicker L. Rehabilitation for Stroke Survivors - A Review. Aust N J of Med 1989;19:400-406.

3. Garraway WM, Alchtar AJ, Hockey L et al. Management of Acute Strokes in the Elderly: Follow Up of a Controlled Trial. Br Med J 1980;281(6244):827-829.

4. Garraway WM, Walton MS et al. The Use of Health and Social Services in the Management of Stroke in the Community: Results from a Controlled Trail. Age Ageing 1981;10:95-104.

5. MacKay F. Stroke Rehabilitation: Is it Worthwhile? Arch Phys Med Rehab 1976;57:546.

6. Millikan $\mathrm{CH}$. Stroke Intensive Care Units: Objectives and Results. Stroke 1979;10:235237.

7. Stevens RS, Ambler NR et al. A Randomised Controlled Trial of a Stroke Rehabilitation Ward. Age Ageing 1984;13:65-75. 